\title{
Demographic and psychiatric correlates of compulsive sexual behaviors in gambling disorder
}

\author{
MEGAN E. COWIE ${ }^{1 *}$, HYOUN S. KIM ${ }^{1}$, DAVID C. HODGINS ${ }^{1}$, DANIEL S. MCGRATH ${ }^{1}$, \\ MARCO D. T. SCANAVINO ${ }^{2,3,4}$ and HERMANO TAVARES ${ }^{3,5}$ \\ ${ }^{1}$ Addictive Behaviours Laboratory, Department of Psychology, University of Calgary, Calgary, AB, Canada \\ ${ }^{2}$ Outpatient Unit for Excessive Sexual Drive and Prevention of Negative Outcomes Associated with Sexual Behavior, \\ Institute of Psychiatry, Clinicas' Hospital, University of São Paulo Medical School, São Paulo, Brazil \\ ${ }^{3}$ Department of Psychiatry, Medical School, University of São Paulo, São Paulo, Brazil \\ ${ }^{4}$ Experimental Pathophysiology, Post-Graduation Program, Medical School, University of São Paulo, São Paulo, Brazil \\ ${ }^{5}$ Impulse Control Disorders and Behavioral Addictions Outpatient Unit, Institute and Department of Psychiatry, \\ University of São Paulo, São Paulo, Brazil
}

(Received: January 21, 2019; revised manuscript received: May 21, 2019; accepted: June 9, 2019)

\begin{abstract}
Background and aims: Gambling disorder (GD) and compulsive sexual behavior (CSB) may commonly co-occur. Yet, the psychiatric correlates of these co-occurring disorders are an untapped area of empirical scrutiny, limiting our understanding of appropriate treatment modalities for this dual-diagnosed population. This study examined the demographic and clinical correlates of CSB in a sample of treatment-seeking individuals with GD $(N=368)$ in São Paulo, Brazil. Methods: Psychiatrists and psychologists conducted semi-structured clinical interviews to identify rates of CSB and other comorbid psychiatric disorders. The Shorter PROMIS Questionnaire was administered to assess additional addictive behaviors. The TCI and BIS-11 were used to assess facets of personality. Demographic and gambling variables were also assessed. Results: Of the total sample, 24 (6.5\%) met diagnostic criteria for comorbid CSB (GD + CSB). Compared to those without compulsive sexual behaviors (GD - CSB), individuals with GD + CSB were more likely to be younger and male. No differences in gambling involvement emerged. Individuals with GD + CSB tended to have higher rates of psychiatric disorders (depression, post-traumatic stress disorder, and bulimia nervosa) and engage in more addictive behaviors (problematic alcohol use, drug use, and exercise) compared to GD - CSB. Those with GD + CSB evidenced less self-directedness, cooperativeness, self-transcendence, and greater motor impulsivity. Logistic regression showed that the predictors of GD + CSB, which remained in the final model, were being male, a diagnosis of bulimia, greater gambling severity, and less self-transcendence. Discussion and conclusion: Given those with GD + CSB evidence greater psychopathology, greater attention should be allocated to this often under studied comorbid condition to ensure adequate treatment opportunities.
\end{abstract}

Keywords: gambling disorder, compulsive sexual behaviors, comorbidity, clinical correlates

\section{INTRODUCTION}

Gambling disorder (GD) is a relatively rare psychiatric disorder, with prevalence of roughly $1 \%$ in the general population (Hodgins, Stea, \& Grant, 2011). GD co-occurs more often than expected with psychiatric disorders including substance use disorders (SUDs; 57.5\%), mood disorders (37.9\%), and anxiety disorders (37.4\%; Lorains, Cowlishaw, \& Thomas, 2011) as well as behavioral addictions like video game addiction (15\%; Jiménez-Murcia et al., 2014), compulsive buying (7.3\%; Grant \& Kim, 2003), and kleptomania (2.1\%; Grant \& Kim, 2003). Importantly, GD has also been found to be comorbid with compulsive sexual behaviors (CSBs), ranging from 3\% to 19.6\% (Black, Kehrberg, Flumerfelt, \& Schlosser, 1997; Grant \& Kim, 2003; Grant \& Steinberg, 2005).
Research suggests that among treatment-seeking samples, individuals with CSBs present with symptoms similar to other addictive behaviors. For example, treatmentseeking individuals with CSBs struggle to control their sexual thoughts, behaviors, or desires, resulting in distress or impairment (Kafka, 2010; Kraus, Voon, \& Potenza, 2016). One of the most influential conceptualizations of CSBs is by Goodman who adapted the criteria for substance dependence in the DSM-IV to manifestations of CSB, conceptualizing it as a sex addiction (SA; Goodman,

\footnotetext{
* Corresponding author: Megan E. Cowie; Addictive Behaviours Laboratory, Department of Psychology, University of Calgary, Room AD 240, 2500 University Drive NW, Calgary, AB T2N 1N4, Canada; Phone: +1 403210 9580; E-mail: megan.cowie@ ucalgary.ca
}

This is an open-access article distributed under the terms of the Creative Commons Attribution-NonCommercial 4.0 International License, which permits unrestricted use, distribution, and reproduction in any medium for non-commercial purposes, provided the original author and source are credited, a link to the CC License is provided, and changes - if any - are indicated. 
2001, 2005). Similar to other addictive behaviors, those with SA evidence sexual thoughts and behaviors that are excessive and repetitive, resulting in distress or impairment. They may also exhibit tolerance, withdrawal, longstanding engagement in excessive sexual behaviors, unsuccessful control of sexual behaviors, long periods of time-seeking sexual opportunities, compromised functioning (e.g., in work), or the continuation of sexual behaviors despite adverse consequences (Goodman, 2001, 2005).

An increasing amount of research has been conducted to provide support for the conceptualization of CSBs as an addiction (Parsons et al., 2013; Reid et al., 2012). Neurobiological evidence suggests that individuals with CSBs have similar neuropathology to those with addictions (Chatzittofis et al., 2016; Kühn \& Gallinat, 2014; Mechelmans et al., 2014; Politis et al., 2013; Voon et al., 2014). For example, like individuals with SUDs, those with CSBs display attentional biases toward their addictive-related stimuli (i.e., sexually explicit cues; Mechelmans et al., 2014). Moreover, similar areas of the brain that become activated in response to substance-related cues become activated when individuals with CSBs are shown sexually explicit cues (Voon et al., 2014).

Further support for the conceptualization of CSBs as addictive behaviors comes from the personality literature. Personality pathology is common in addictive disorders, and research suggests there are similarities between the personality profiles of those with GD and CSBs. For example, heightened novelty seeking and impulsivity as well as lower self-directedness are common among individuals with GD (Black et al., 2015) and CSBs (do Amaral, Abdo, Tavares, \& Scanavino, 2015; Fuentes, Tavares, Camargo, \& Gorenstein, 2000; Raymond, Coleman, \& Miner, 2003).

In contrast, previous research also suggests that there are personality differences in individuals with GD versus CSBs. Specifically, while people with GD report less cooperativeness (Janiri, Martinotti, Dario, Schifano, \& Bria, 2007; Martinotti et al., 2006; Nordin \& Nylander, 2007), greater harm avoidance (Nordin \& Nylander, 2007), and selftranscendence (Martinotti et al., 2006; Nordin \& Nylander, 2007), a similar pattern of personality characteristics has not been reported among those with CSBs. Direct comparisons of the two populations have found that those with GD display higher levels of novelty seeking, harm avoidance, reward dependence, persistence, selfdirectedness, and cooperativeness compared to people with CSBs (Farré et al., 2015). However, although the personality profiles of two populations have been directly compared, the personality features of the comorbid condition are not well understood. Understanding the personality profiles of this comorbid condition has important implications and may directly influence and inform treatment outcomes (Leblond, Ladoucer, \& Blaszczynski, 2003).

Previous literature suggests CSBs are common co-occurring diagnoses among disordered gamblers. Specifically, co-occurrence rates of CSBs range from 3\% in community samples (Black et al., 1997) to $8.3 \%$ and $19.6 \%$ in treatment-seeking samples (Grant \& Kim, 2003; Grant \& Steinberg, 2005). This is not surprising given the high rates of co-occurring addictive behaviors in GD (Grant \& Kim, 2003; Jiménez-Murcia et al., 2014). The empirical literature provides several theories to explain these high rates of comorbidity, one of which is the impulsivity-compulsivity construct (Hollander, 1993; Hollander \& Wong, 1995a, 1995b; McElroy, Phillips, \& Keck, 1994). This construct posits that disorders can be classified as lying along an impulsive to compulsive spectrum. GD, CSBs, SUDs, and bulimia nervosa have been proposed to lie closer to the impulsive end of the spectrum (Hollander, 2005; McElroy et al., 1994). As a result, these disorders are thought to share certain commonalities such as greater impulsivity (Farstad et al., 2015) and urgency (Fischer \& Smith, 2008), which may explain the high degree of overlap between these disorders. Providing further support for this supposition, both individuals with GD and CSB demonstrate greater levels of impulsivity (Forbush et al., 2008; Hodgins \& Holub, 2015; Miner, Raymond, Mueller, Lloyd, \& Lim, 2009; Raymond et al., 2003), and emotion dysregulation (Cashwell, Giordano, King, Lankford, \& Henson, 2017; Jauregui, Estévez, \& Urbiola, 2016; Williams, Grisham, Erskine, \& Cassedy, 2012). Moreover, independent investigations of individuals with GD and individuals with CSBs reveal similar co-occurring conditions, with mood, anxiety, and SUDs being the most frequent comorbidities for both GD and CSBs (Lorains et al., 2011; Raymond et al., 2003).

Despite the common co-occurrence of GD and CSB and their similarities, literature examining characteristics of individuals with a dual diagnosis of GD and CSB is sparse. To our knowledge, only one study has compared individuals with GD without comorbid CSB (GD - CSB) to those with comorbid CSB (GD + CSB). Grant and Steinberg (2005) recruited 225 outpatients who met criteria for GD. Fortyfour $(19.6 \%)$ met criteria for GD + CSB compared to 181 participants who met criteria for GD - CSB. Compared to those with GD - CSB, individuals with GD + CSB were more likely to be male (Grant \& Steinberg, 2005). While both groups experienced high rates of major depressive disorder and SUDs, there were no differences among these, or other, psychiatric domains. Although no psychiatric differences were found, the authors note the relatively high incidence of CSB among disordered gamblers, with GD + CSB occurring more often than expected.

Although Grant and Steinberg (2005) examined the demographic and clinical correlates of $\mathrm{GD}+\mathrm{CSB}$, this literature was published over a decade ago and thus an update and extension of these findings are warranted. For example, the concept of behavioral addictions has gained increasingly greater traction over the years (Billieux, Schimmenti, Khazaal, Maurage, \& Heeren, 2015). This increased relevancy may have resulted in a greater likelihood of clinicians assessing behavioral addictions like CSB and individuals endorsing symptoms, which may have affected its prevalence and correlates (Granero et al., 2016). Finally, no literature has also examined the personality or gambling behavior correlates of GD + CSB. Given certain features of personality are risk factors for pathology (Steel \& Blaszczynski, 1998) and treatment dropout (Leblond et al., 2003), it is important to understand the personality profile of this comorbid population.

Specifically, the clinical, psychiatric, behavioral, and personality correlates of this concurrent diagnoses have been comparatively overlooked. Comorbidity often 
engenders greater impairment in functioning including greater gambling severity, greater duration of gambling problems, more absences from work (Ladd \& Petry, 2003), and psychopathology (Abdollahnejad, Delfabbro, \& Denson, 2014; Cunningham-Williams, Cottler, Compton, Spitznagel, \& Ben-Abdallah, 2000; Ladd \& Petry, 2003). Comorbidity also impedes the recovery process (Hodgins \& el-Guebaly, 2010) compared to those without a comorbid condition. Thus, examining the correlates of this concurrent disorder may elucidate important clinical information to impact treatment planning and outcomes for this population.

In this study, we aimed to further investigate and extend the findings of Grant and Steinberg (2005) by examining the demographic, behavioral, clinical, and personality correlates of a sample of treatment-seeking disordered gamblers with $(\mathrm{GD}+\mathrm{CSB})$ and without $(\mathrm{GD}-\mathrm{CSB})$ comorbid CSB. Given the existing literature, we hypothesized that GD +CSB would be more frequent in men (Grant \& Steinberg, 2005). Furthermore, we hypothesized that GD + CSB would be associated with greater psychiatric comorbidities compared to those with GD-CSB. Finally, we hypothesized that GD + CSB would be associated with heightened novelty seeking and impulsivity, as well as lower self-directedness.

\section{METHODS}

\section{Participants and procedures}

Participants $(N=368)$ were patients seeking treatment for GD between the years of 2006 and 2015 at the Gambling Outpatient Unit of the Institute of Psychiatry at the University of São Paulo Hospital. Participation was voluntary and participants were informed that their decision to participate would have no impact on their treatment. Inclusion criteria were: (a) primary diagnosis of GD, (b) age 18 years or over, and (c) informed consent to participate in research. Exclusion criteria were: (a) cognitive impairments that inhibited understanding of the research protocol, (b) acute psychosis, and (c) a psychiatric presentation requiring admission to the inpatient unit.

Registered psychologists and psychiatrists who specialized in GD assigned diagnoses of GD using a structured clinical interview with DSM-IV criteria. Participants also completed a standardized research protocol at intake, which included self-report questionnaires and a psychiatric interview.

Due to the absence of diagnostic criteria for CSB when the project began, CSB was diagnosed with a structured psychiatric interview using Goodman's criteria. Goodman's criteria contain 13 items, which assess CSBs across seven dimensions related to substance use criteria: tolerance, withdrawal, engagement in sexual behaviors, difficulty controlling engagement in sexual behaviors, great time seeking out engagement in sexual behaviors, impairment in functioning, and continued engagement in sexual behaviors, despite adverse effects (Goodman, 2001, 2005). Participants were diagnosed with CSB if they endorsed three or more of Goodman's dimensions and through clinician judgment. Participants were excluded if their engagement in CSB occurred during an episode of mania or hypomania or could be explained by another mental disorder, physical condition, or the physiological effects of a substance. Goodman's criteria have been used in previous research to diagnose samples with CSBs (do Amaral et al., 2015; Scanavino et al., 2016).

\section{Measures}

Demographics. Age, sex, ethnicity, marital status, sexual orientation, years of education, and monthly income were obtained through a demographic questionnaire derived from a previously developed semi-structured interview (Tavares et al., 2003).

Gambling behaviors. The following gambling behaviors were evaluated using a self-report questionnaire adapted from the Addiction Severity Index (Petry, 2003): age at which the individual started to bet regularly (at least once per month), hours gambled each week, days gambled in the past month, money lost in the past month, and days in which the individual experienced gambling-related problems in the past month. The Portuguese version of this questionnaire exhibits good convergent validity with other measures of gambling severity (Galetti \& Tavares, 2017).

Gambling severity was assessed using the 12-item Portuguese adaptation of the Gambling Symptom Assessment Scale (G-SAS; Galetti \& Tavares, 2017; Kim, Grant, Potenza, Blanco, \& Hollander, 2009). Items are rated on a 0-4 Likert scale with higher scores suggesting greater gambling symptom severity. The G-SAS demonstrates good convergent validity with other tests of gambling symptom severity (Galetti \& Tavares, 2017). Finally, gamblingrelated cognitive distortions regarding luck/perseverance and the illusion of control were assessed using the 21-item Portuguese version of the Gamblers' Beliefs Questionnaire (GBQ; Steenbergh, Meyers, May, \& Whelan, 2002). Each item on the GBQ is rated on a 7-point Likert scale, with lower scores suggesting greater cognitive distortions. The scores on this scale were reverse-coded in this study; higher scores suggest greater gambling-related cognitive distortions.

Psychiatric comorbidities. The Portuguese version of the Mini-International Neuropsychiatric Interview (MINI) was used to assess current psychiatric comorbidities such as mood and anxiety disorders, obsessive-compulsive disorders, eating disorders, suicidality, and post-traumatic stress disorder (PTSD; Amorim, 2000). The MINI is a brief psychiatric interview that has strong psychometric properties comparable to other semi-structured interviews such as the Structured Clinical Interview for the DSM (Lecrubier et al., 1997).

Addictive behaviors. The Portuguese version of the Shorter PROMIS Questionnaire (SPQ) was used to assess addictive behaviors, such as the use of nicotine, prescription and recreational drugs, alcohol, caffeine, sex, gambling, exercise, shopping, work, dominant and submission relationships, and submissive compulsive helping (Christo et al., 2003). This self-report measure contains 160 items rated on a $0-5$ Likert scale and purports excellent psychometric properties (Christo et al., 2003). Higher scores on the SPQ suggest greater problem severity. Submissive and dominant helping/relationships were excluded from analyses due to insufficient empirical evidence supporting their classifications as addictive behaviors. 
Personality variables. The Portuguese version of the Temperament and Character Inventory (TCI) was used to assess seven personality dimensions comprising four temperaments, such as reward dependence, novelty seeking, persistence, and harm avoidance, and three characters, such as cooperativeness, self-transcendence, and selfdirectedness (Cloninger, Przybeck, Svrakic, \& Wetzel, 1994; Fuentes et al., 2000). The Portuguese version of the TCI has similar internal consistency to the original version (Fuentes et al., 2000). The TCI is extensively used to assess personality in individuals with SUDs (Basiaux et al., 2001) and behavioral addictions (Janiri et al., 2007). The TCI has also been used in populations presenting with GD (Black et al., 2015) and CSBs (do Amaral et al., 2015). Impulsivity was measured using the Portuguese version of the Barratt Impulsiveness Scale - 11 (BIS-11; Malloy-Diniz et al., 2010; Patton, Stanford, \& Barratt, 1995). The BIS-11 contains 30 items assessing dimensions of impulsivity including motor, attentional, and non-planning. In addition, it provides a total impulsivity score. Items are rated on a $0-4$ scale, with higher scores being indicative of greater impulsivity.

\section{Statistical analyses}

Demographics, gambling behaviors, psychiatric comorbidities, addictive behaviors, and personality characteristics were compared between GD + CSB and GD - CSB using univariate analyses. $\chi^{2}$ and Fischer's exact tests were performed on categorical variables, and independent samples $t$-tests were performed on continuous variables. The Kolmogorov-Smirnov test was used to assess normality and, if violated, non-parametric Mann-Whitney $U$ tests were conducted.

To identify the importance of each predictor and correct for multiple comparisons, a backward binary logistic regression was conducted using diagnostic group as the dependent variable $(0=\mathrm{GD}-\mathrm{CSB}$ and $1=\mathrm{GD}+\mathrm{CSB})$, and variables with $p<.10$ from the univariate analyses entered simultaneously as predictor variables (Tabachnick \& Fidell, 2007). To determine whether our pattern of missing data was missing completely at random (MCAR), we conducted a Little's MCAR test. This test was non-significant, $\chi^{2}(3,660)=3,563.15, p=.872$, indicating the data were missing completely at random and thus listwise deletion was used for observations with missing values.

\section{Ethics}

This research was carried out in accordance with the ethics committee of the institutional review board of the Clinics Hospital of the University of São Paulo in Brazil. All participants were required to provide written, informed consent to participate.

\section{RESULTS}

\section{Demographics and gambling behaviors}

Thirty-two $(8.7 \%)$ of the participants endorsed at least one dimension of CSB. However, three participants who endorsed at least one dimension of CSB were excluded due to their symptoms occurring exclusively during episodes of mania/hypomania and/or being due to another mental disorder, medical condition, physiological effects of a substance, or changes in libido within a relationship (Goodman, 2001, 2005). Five participants who endorsed at least one dimension of CSBs were also excluded based on clinician judgment. That said, of the five participants, only one participant endorsed three or more dimensions on Goodman's criteria. Thus, the final sample consisted of 24 (6.5\%) participants with GD + CSB and 344 (93.5\%) without a diagnosis of CSB (see Table 1 for endorsement of Goodman's criteria). To provide confidence in our diagnosis, we compared scores on the sex subscale of PROMIS. Individuals with GD + CSB scored significantly higher $(M=19.93, \quad S D=15.89) \quad$ compared to $\mathrm{GD}-\mathrm{CSB}$ $(M=6.35, S D=8.09), U=931.50, p=.001$. Thus, our structured psychiatric interview for CSB demonstrated good convergent validity with the PROMIS subscale of SA.

With regard to demographic characteristics, those with GD + CSB tended to be younger and were more likely to be male compared to GD - CSB. No other demographic differences or significant differences in gambling behaviors were found (Table 2).

\section{Psychiatric comorbidities}

Those who met criteria for GD + CSB were significantly more likely to be diagnosed with a current major depressive episode, PTSD, and bulimia nervosa compared to GD - CSB (Table 3). Those who met criteria for GD + CSB $(M=3.00$, $S D=1.85)$ were more likely to be diagnosed with additional comorbidities compared to those with GD - CSB $(M=1.93$, $S D=1.63), U=1,624.00, p=.004$. No other significant differences were found between the groups.

\section{Addictive behaviors}

Compared to those with GD-CSB, individuals with GD + CSB were more likely to report problematic use of alcohol, recreational drugs, and problematic engagement in compulsive exercising (Table 4). No other significant differences were found between the groups.

Table 1. Endorsement of the seven dimensions of Goodman's criteria of individuals with comorbid gambling disorder and compulsive sexual behaviors

\begin{tabular}{lcc}
\hline & \multicolumn{2}{c}{$\begin{array}{c}\text { Gambling disorder } \\
\text { with compulsive sexual } \\
\text { behaviors }(n=24)\end{array}$} \\
\cline { 2 - 3 } Goodman's criteria & $n$ & $\%$ \\
\hline Excessive engagement & 6 & 25.0 \\
Loss of control & 15 & 62.5 \\
Withdrawal & 15 & 62.5 \\
Tolerance & 11 & 45.8 \\
Preoccupation & 13 & 54.2 \\
Continued engagement despite harm & 11 & 45.8 \\
Impairment in functioning & 21 & 87.5 \\
\hline
\end{tabular}


Table 2. Demographic characteristics and gambling behaviors of individuals with and without comorbid gambling disorder and compulsive sexual behaviors

\begin{tabular}{|c|c|c|c|c|c|c|c|c|}
\hline \multirow[b]{2}{*}{ Variables } & \multicolumn{3}{|c|}{$\begin{array}{l}\text { Gambling disorder without } \\
\text { compulsive sexual behaviors } \\
\qquad(n=344)\end{array}$} & \multicolumn{3}{|c|}{$\begin{array}{l}\text { Gambling disorder with } \\
\text { compulsive sexual behaviors } \\
(n=24)\end{array}$} & \multirow[b]{2}{*}{ Test } & \multirow[b]{2}{*}{$p$} \\
\hline & $N$ & $\%$ & $M(S D)$ & $N$ & $\%$ & $M(S D)$ & & \\
\hline Age & & & $47.87(12.38)$ & & & $41.96(10.31)$ & $U=2,823.00^{\mathrm{a}}$ & $.031 *$ \\
\hline Sex & & & & & & & $\chi^{2}=12.05$ & $.001^{\mathrm{b} *}$ \\
\hline Male & 188 & 55.5 & & 22 & 91.7 & & & \\
\hline Female & 151 & 44.5 & & 2 & 8.3 & & & \\
\hline Ethnic group & & & & & & & & $.466^{\mathrm{c}}$ \\
\hline Caucasian & 240 & 72.1 & & 16 & 72.7 & & & \\
\hline African American & 30 & 9.0 & & 1 & 4.5 & & & \\
\hline Mixed race & 51 & 15.3 & & 3 & 13.6 & & & \\
\hline Asian & 9 & 2.7 & & 2 & 9.1 & & & \\
\hline Other & 3 & 0.9 & & 0 & 0.0 & & & \\
\hline Marital status & & & & & & & & $.571^{\mathrm{c}}$ \\
\hline In a relationship & 175 & 52.7 & & 11 & 47.8 & & & \\
\hline Single & 94 & 28.3 & & 9 & 39.1 & & & \\
\hline Other & 63 & 19.0 & & 3 & 13.0 & & & \\
\hline Sexual orientation & & & & & & & & $.350^{\mathrm{c}}$ \\
\hline Heterosexual & 320 & 95.5 & & 20 & 90.9 & & & \\
\hline Homosexual & 12 & 3.6 & & 2 & 9.1 & & & \\
\hline Bisexual & 3 & 0.9 & & 0 & 0.0 & & & \\
\hline Years of education & & & $11.05(4.70)$ & & & $11.78(6.22)$ & $U=3,745.50^{\mathrm{a}}$ & .805 \\
\hline Monthly income in Brazilian Reais & & & $5,858.75(7,692.34)$ & & & $8,301.95(10,981.24)$ & $U=2,857.50^{\mathrm{a}}$ & .165 \\
\hline Age started regular betting & & & $32.35(13.66)$ & & & $26.59(10.29)$ & $U=2,790.50$ & .059 \\
\hline Hours spent gambling (per day) & & & $6.67(4.94)$ & & & $8.48(5.27)$ & $U=2,661.50$ & .122 \\
\hline G-SAS & & & $26.48(11.25)$ & & & $29.65(8.77)$ & $U=1,879.50$ & .252 \\
\hline $\begin{array}{l}\text { Gambling problems (no. of days in } \\
\text { past month) }\end{array}$ & & & $19.51(12.23)$ & & & $15.59(12.50)$ & $U=3,067.50$ & .151 \\
\hline Days gambled (past month) & & & $8.91(9.38)$ & & & $11.82(11.58)$ & $U=3,273.50$ & .399 \\
\hline Dollars lost (past month) & & & $2,351.48(6,687.79)$ & & & $7,500.45(13,627.75)$ & $U=3,276.50$ & .403 \\
\hline GBQ & & & $88.77(26.87)$ & & & $79.89(28.91)$ & $t=1.35$ & .179 \\
\hline
\end{tabular}

Note. G-SAS: Gambling Symptom Assessment Scale; GBQ: Gamblers' Beliefs Questionnaire; M: mean; SD: standard deviation.

${ }^{a}$ Mann-Whitney $U$ test. ${ }^{\mathrm{b}} \chi^{2}$ test. ${ }^{\mathrm{c}}$ Fishers' exact test was used as expected cell counts were less than 5 .

*Significance at $p<.05$.

\section{Personality variables}

Individuals with GD $+\mathrm{CSB}$ were more likely to report less levels of self-directedness, cooperativeness, and selftranscendence (Table 5). They were also more likely to endorse greater motor impulsivity. No other differences were found between the two groups.

\section{Binary logistic regression}

The following variables were entered into the binary logistic regression: sex, age of participant, age participant started making regular bets, major depressive episode, PTSD, obsessive-compulsive disorder, agoraphobia, bulimia nervosa, alcohol, gambling, recreational drug use, exercise, self-directedness, cooperativeness, self-transcendence, and motor impulsivity. The backward binary logistic regression yielded a final model with four significant predictor variables: male sex, bulimia nervosa, gambling severity, and self-transcendence (Table 6). The overall model fit was significant, $\chi^{2}(4)=21.79, p<.001$, and had a classification accuracy of $92.4 \%$. Those with GD + CSB were more likely to be male $(\mathrm{OR}=20.89,95 \% \mathrm{CI}=[1.95,224.21])$, meet criteria for bulimia nervosa $(\mathrm{OR}=8.17,95 \% \mathrm{CI}=[1.21$, $55.44])$, evidence greater gambling severity $(\mathrm{OR}=1.07$, $95 \% \mathrm{CI}=[1.00,1.15])$, and report less self-transcendence $(\mathrm{OR}=0.90,95 \% \mathrm{CI}=[0.81,1.00])$.

\section{DISCUSSION}

In this study, we examined the demographic, clinical, and personality correlates of treatment-seeking disordered gamblers with $(\mathrm{GD}+\mathrm{CSB})$ and without $(\mathrm{GD}-\mathrm{CSB})$ comorbid CSB. Out of the 368 treatment-seeking disordered gamblers, $6.5 \%(n=24)$ met criteria for GD + CSB. This rate is higher than community samples (Black et al., 1997) but lower than what has been observed among treatment-seeking gamblers 
Table 3. Comparison of current psychiatric comorbidities between individuals with and without comorbid gambling disorder and compulsive sexual behaviors

\begin{tabular}{|c|c|c|c|c|c|c|}
\hline \multirow[b]{2}{*}{ Psychiatric comorbidity } & \multicolumn{2}{|c|}{$\begin{array}{l}\text { Gambling disorder without compulsive } \\
\text { sexual behaviors }(n=344)\end{array}$} & \multicolumn{2}{|c|}{$\begin{array}{c}\text { Gambling disorder with compulsive } \\
\text { sexual behaviors }(n=24)\end{array}$} & \multirow[b]{2}{*}{$\chi^{2}$} & \multirow[b]{2}{*}{$p$} \\
\hline & $n$ & $\%$ & $n$ & $\%$ & & \\
\hline Major depressive episode & 155 & 49.2 & 18 & 75.0 & 5.94 & $.015^{*}$ \\
\hline Suicidality & 123 & 39.0 & 12 & 50.0 & 1.12 & .291 \\
\hline Panic disorder & 37 & 11.7 & 4 & 16.7 & & $.512^{\mathrm{a}}$ \\
\hline Social phobia & 34 & 10.8 & 5 & 20.8 & & $.174^{\mathrm{a}}$ \\
\hline PTSD & 13 & 4.1 & 5 & 20.8 & & $.005^{\mathrm{a} *}$ \\
\hline GAD & 88 & 36.8 & 10 & 45.5 & 0.64 & .424 \\
\hline OCD & 13 & 4.1 & 3 & 12.5 & & $.095^{\mathrm{a}}$ \\
\hline Agoraphobia & 90 & 28.6 & 11 & 45.8 & 3.18 & .075 \\
\hline Bulimia nervosa & 32 & 10.2 & 6 & 25.0 & & $.039^{\mathrm{a} *}$ \\
\hline
\end{tabular}

Note. PTSD: post-traumatic stress disorder; GAD: generalized anxiety disorder; OCD: obsessive-compulsive disorder.

${ }^{a}$ Fishers' exact test was used as expected cell counts were less than 5 .

* Significance at $p<.05$.

Table 4. Comparison of addictive behaviors as measured by the Shorter PROMIS Questionnaire (SPQ) between individuals with and without comorbid gambling disorder and compulsive sexual behaviors

\begin{tabular}{|c|c|c|c|c|c|c|}
\hline \multirow[b]{2}{*}{ Addictive behaviors } & \multicolumn{2}{|c|}{$\begin{array}{l}\text { Gambling disorder without compulsive } \\
\text { sexual behaviors }(n=344)\end{array}$} & \multicolumn{2}{|c|}{$\begin{array}{l}\text { Gambling disorder with compulsive sexual } \\
\text { behaviors }(n=24)\end{array}$} & \multirow[b]{2}{*}{ Test $(U)$} & \multirow[b]{2}{*}{$p$} \\
\hline & $M$ & $S D$ & $M$ & $S D$ & & \\
\hline Alcohol & 9.15 & 12.31 & 18.31 & 14.60 & $1,345.50$ & $.014^{*}$ \\
\hline Shopping & 13.04 & 10.64 & 13.19 & 11.28 & $2,218.00$ & .985 \\
\hline Food bingeing & 14.87 & 12.37 & 16.93 & 15.36 & $1,950.50$ & .866 \\
\hline Food starving & 8.75 & 7.49 & 11.25 & 10.87 & $2,010.00$ & .561 \\
\hline Tobacco & 16.33 & 17.04 & 23.20 & 18.71 & $1,576.50$ & .116 \\
\hline Gambling & 31.34 & 12.94 & 37.31 & 11.25 & $1,529.00$ & .056 \\
\hline Drugs & 3.78 & 8.48 & 10.13 & 16.13 & $1,520.50$ & $.016^{*}$ \\
\hline Work & 16.43 & 9.64 & 21.63 & 12.27 & $1,661.50$ & .130 \\
\hline Caffeine & 7.29 & 9.37 & 10.47 & 10.45 & $1,513.00$ & .102 \\
\hline Prescription drugs & 7.20 & 9.56 & 9.06 & 12.29 & $2,125.00$ & .517 \\
\hline Exercise & 9.62 & 8.61 & 15.94 & 10.51 & $1,300.50$ & $.010^{*}$ \\
\hline
\end{tabular}

Note. $U$ : Mann-Whitney $U$ test; $M$ : mean; $S D$ : standard deviation.

*Significance at $p<.05$.

Table 5. Comparison of personality and impulsiveness correlates between individuals with and without comorbid Gambling disorder and compulsive sexual behaviors

\begin{tabular}{|c|c|c|c|c|c|c|}
\hline \multirow[b]{2}{*}{ Personality variables } & \multicolumn{2}{|c|}{$\begin{array}{l}\text { Gambling disorder without compulsive } \\
\text { sexual behaviors }(n=344)\end{array}$} & \multicolumn{2}{|c|}{$\begin{array}{l}\text { Gambling disorder with compulsive } \\
\text { sexual behaviors }(n=24)\end{array}$} & \multirow[b]{2}{*}{ Test } & \multirow[b]{2}{*}{$p$} \\
\hline & $M$ & $S D$ & $M$ & $S D$ & & \\
\hline Novelty seeking & 23.60 & 5.47 & 25.33 & 4.84 & $U=1,672.00$ & .247 \\
\hline Harm avoidance & 19.43 & 5.56 & 19.40 & 5.77 & $t=0.02$ & .985 \\
\hline Reward dependence & 13.69 & 3.83 & 13.21 & 2.55 & $U=1,702.00$ & .515 \\
\hline Persistence & 4.24 & 1.97 & 4.29 & 2.09 & $U=2,276.00$ & .797 \\
\hline Self-directedness & 22.68 & 7.23 & 18.79 & 8.19 & $U=1,177.00$ & $.039 *$ \\
\hline Cooperativeness & 28.42 & 5.46 & 25.14 & 4.91 & $U=1,150.50$ & $.014 *$ \\
\hline Self-transcendence & 18.00 & 5.60 & 15.13 & 7.23 & $U=1,370.50$ & $.046^{*}$ \\
\hline BIS-total & 72.93 & 10.23 & 76.64 & 11.81 & $U=1,800.00$ & .146 \\
\hline BIS-attention & 19.63 & 3.74 & 20.46 & 4.35 & $U=2,428.00$ & .551 \\
\hline BIS-motor & 21.63 & 4.86 & 23.80 & 5.08 & $U=1,764.50$ & $.047 *$ \\
\hline BIS-non-planning & 31.03 & 4.07 & 31.96 & 4.82 & $U=2,176.00$ & .371 \\
\hline
\end{tabular}

Note. $U$ : Mann-Whitney $U$ test; BIS: Barratt Impulsiveness Scale - 11; $M$ : mean; $S D$ : standard deviation.

*Significance at $p<.05$. 
Table 6. Backward binary logistic regression with group coded $(0=\mathrm{GD}-\mathrm{CSB}$ and $1=\mathrm{GD}+\mathrm{CSB})$ and variables with $p \leq .10$ entered as predictors

\begin{tabular}{lccrcr}
\hline & Wald & & Exp & \multicolumn{2}{c}{ 95\% for $\operatorname{Exp}(B)$} \\
\cline { 5 - 6 } Variables & $\chi^{2}$ & $p$ & $(B)$ & Lower & Upper \\
\hline Sex & 6.30 & .012 & 20.89 & 1.95 & 224.21 \\
$\begin{array}{c}\text { Bulimia } \\
\text { nervosa }\end{array}$ & 4.63 & .031 & 8.17 & 1.21 & 55.44 \\
$\begin{array}{c}\text { Gambling } \\
\text { severity }\end{array}$ & 3.94 & .047 & 1.07 & 1.00 & 1.15 \\
$\begin{array}{c}\text { Self- } \\
\text { transcendence }\end{array}$ & 3.97 & .046 & .897 & 0.81 & 1.00 \\
Constant & 9.52 & .002 & .003 & & \\
\hline
\end{tabular}

Note. GD-CSB: gambling disorder without compulsive sexual behaviors; GD + CSB: gambling disorder with compulsive sexual behaviors; Dependent variable: presence of compulsive sexual behavior; Predictors: sex, age, age of onset of regular gambling (at least once per month), major depressive episode, post-traumatic stress disorder, obsessive-compulsive disorder, agoraphobia, bulimia nervosa, alcohol, gambling, drugs, exercise, self-directedness, cooperativeness, self-transcendence, and motor impulsiveness.

in earlier studies (Grant \& Kim, 2003; Grant \& Steinberg, 2005). We feel there are two possible reasons for these different prevalence rates. First, Grant and Steinberg (2005) used the Minnesota Impulsive Disorders Interview (Grant, 2008). This measure is largely self-report, with participants providing "yes" or "no" responses to diagnostic questions. In this study, we used a structured clinical interview to provide diagnosis based on Goodman's criteria. It is possible that the use of a structured clinical interview may have been a more stringent assessment of CSB, lowering the rate of CSB in our sample.

Second, it is possible that our recruitment strategy may have resulted in these differing rates. For example, both Grant and Kim (2003) and Grant and Steinberg (2005) recruited participants through study advertisements and referrals. In this study, no advertising or referrals were used, as individuals in our sample were self-referring for GD, which was their primary diagnosis. This may have decreased the prevalence of CSBs relative to GD, given their primary presenting concern was GD, which was severe enough to warrant our sample seeking treatment. Importantly, given our participants self-referred for treatment, the prevalence of CSBs in our sample may be more reflective of a clinical sample.

Consistent with previous literature (Grant \& Steinberg, 2005), those with GD + CSB were more likely to be male compared to those with GD - CSB. In addition, individuals with GD + CSB were more likely to be younger compared to those with GD-CSB. Although younger age was not a significant predictor in our final model, these findings are largely consistent with Grant and Steinberg's (2005) study. Specifically, individuals with GD + CSB tended to be of a younger age in Grant and Steinberg's (2005) study, although their finding was not statistically significant. No other demographic variables or gambling behaviors were significantly different between the two populations. As our sample was composed of treatment-seeking gamblers, it is possible that we had reached a ceiling in terms of finding differences in gambling behaviors between the two groups. In contrast to previous literature (Grant \& Steinberg, 2005), individuals with GD + CSB evidenced greater psychopathology compared to those without comorbid CSB. Specifically, those with GD + CSB reported greater symptoms of major depression, PTSD, and bulimia nervosa, with bulimia nervosa being the only significant predictor in the final model. Furthermore, they reported greater engagement in addictive behaviors such as problematic alcohol and drug use and excessive exercise, with gambling severity being the only significant predictors in the final model. Although this finding is in contrast to Grant and Steinberg (2005), it is more broadly supported by the literature, which has shown that those with comorbid conditions tend to evidence greater psychopathology compared to those without comorbid conditions (Abdollahnejad et al., 2014; CunninghamWilliams et al., 2000; Ladd \& Petry, 2003).

The rates of comorbid psychopathology among GD + CSB converge and diverge with the impulsivitycompulsivity construct model. Specifically, GD + CSB reported greater levels of addictive behaviors and bulimia nervosa disorders that are characterized by impulsivity. On the other hand, the most frequent co-occurring mental health comorbidity was major depression, which is conceptualized as an internalizing disorder. However, research has shown that individuals with depression also report elevated levels of impulsivity, compared to those without depression (Peluso et al., 2007), suggesting certain aspects of impulsivity may be characteristics of both depression and psychiatric disorders characterized predominantly by impulsivity, such as GD and SUDs. As impulsivity is a multifaceted construct (Evenden, 1999), future research examining which facets of impulsivity link psychiatric disorders including addictive behaviors like gambling and CSBs with other psychiatric disorders including major depression would be highly informative.

With regard to impulsivity, those with GD + CSB reported greater levels of motor impulsivity compared to those without GD-CSB, although this variable was not significant in the final model. The role of motor impulsivity in GD + CSB might be attributed to the fact that compared to other addictive behaviors, sexual compulsions involves greater motor components. However, more research with larger sample sizes is needed to replicate our findings. Despite marginal, given motor impulsivity was more severe in those with a dual diagnosis of GD and CSB, more attention should be provided to those presenting with this comorbidity. In addition, although no other differences in impulsivity emerged in our sample, it is interesting that impulsivity was in fact present in both GD-CSD and $\mathrm{GD}+\mathrm{CSB}$, given the prominent role of impulsivity in addiction populations (Kim \& Hodgins, 2018). In addition, more recent models of impulsivity have suggested that urgency, a facet of impulsivity, may play a particularly important role in addictive disorders (Cyders \& Smith, 2008; Smith \& Cyders, 2016). Thus, future research that comprehensively examines impulsivity, including urgency, would be highly informative. Indeed, recent research has found that urgency may be of particular importance in understanding comorbid GD and substance (Boothby, Kim, Romanow, Hodgins, \& McGrath, 2017) and behavioral 
addictions (Farstad et al., 2015). With respect to personality, those with GD + CSB reported less self-directedness, cooperativeness, and self-transcendence compared to those with GD - CSB, with self-transcendence being the only significant predictor in the final model. Previous literature has shown that compared to non-problem gamblers, individuals with GD tend to report less self-directedness, less cooperativeness, but greater self-transcendence (Janiri et al., 2007; Martinotti et al., 2006). However, individuals whose gambling problems began at an earlier age tend to report less self-transcendence compared to those whose gambling problems began at a later age (Jiménez-Murcia et al., 2016). In this study, those with GD + CSB tended to begin engaging in problematic gambling behavior at a younger age compared to those with GD - CSB, although these findings did not reach statistical significance. Such differences in personality domains have been shown to be related to an increase in clinical severity and negative health outcomes. For example, low self-directedness has been associated with higher severity of the excessive sexual behaviors and with intentional unsafe sex in a sample of sexually compulsive men who have sex with men (do Amaral et al., 2015). Future research is needed to test this hypothesis.

In the binary logistic regression, GD + CSB were more likely to be male and meet diagnostic criteria for bulimia nervosa compared to those with GD - CSB. Furthermore, they were more likely to evidence greater severity of gambling problems and less self-transcendence. As previously mentioned, a greater proportion of men being diagnosed with the comorbid condition are consistent with prior literature (Grant \& Steinberg, 2005). In this study, men were approximately $21 \times$ more likely to be diagnosed with the comorbid condition compared to women. Furthermore, individuals with GD + CSB were approximately $8 \times$ more likely to meet criteria for bulimia nervosa. Although individuals in our sample were more likely to have greater severity of gambling problems and less self-transcendence, these effect sizes were small.

Our findings may provide further evidence for the impulsivity-compulsivity construct model whereby multiple psychiatric disorders may be best conceptualized as different disorders, which manifest through similar underlying vulnerabilities, such as impulsivity (Lacey \& Evans, 1986). For example, previous literature has found that both individuals who engage in problem gambling and CSBs often do so as a means of coping with negative affect (Bancroft \& Vukadinovic, 2004; Blaszczynski \& Nower, 2002; Moon, Lister, Milosevic, \& Ledgerwood, 2017). This self-regulation strategy is also observed among individuals with bulimia nervosa (Berg et al., 2013), for whom binge eating episodes, often conceptualized as an addictive behavior (de Vries \& Meule, 2016; Umberg, Shader, Hsu, $\&$ Greenblatt, 2012), serve as reprieve from negative mood states. Taken together, our findings suggest that impulsivity and negative affect (i.e., urgency) may serve as unifying self-regulatory factors of psychopathology for individuals with GD + CSB and thus one might seek to target these vulnerabilities through engagement in addictive behaviors including gambling, sex, and binge eating. Future research should investigate whether targeting these similar underlying pathologies might reduce the symptoms associated with GD + CSB.
Overall, this study provides support for the conceptualization of CSBs as an addiction. Clusters of pathology found in our sample are those who are commonly reported among other SUDs (Conway, Compton, Stinson, \& Grant, 2006) and behavioral addictions (González-Bueso et al., 2018; Granero et al., 2016). For example, depression is among the most highly co-occurring comorbidity in SUDs (Conway et al., 2006) as well as gambling (Black \& Moyer, 1998) and other proposed behavioral addictions like compulsive buying (Granero et al., 2016), Internet gaming (González-Bueso et al., 2018), and kleptomania (Grant \& Kim, 2002). In addition, PTSD also frequently co-occurs with SUDs (Kessler, Sonnega, Bromet, Hughes, \& Nelson, 1995), gambling (Kessler et al., 2008), and other purported behavioral addictions like Internet use disorder (Hsieh et al., 2016) and bulimia nervosa (Tagay, Schlottbohm, ReyesRodriguez, Repic, \& Senf, 2014).

As has been theorized, addictive disorders, including both behavioral and substance addictions, have been considered to arise from similar underlying or transdiagnostic syndromes (Kim \& Hodgins, 2018; Shaffer et al., 2004). From this perspective, addictive disorders share commonalities yet also manifest distinct features. Indeed, in this study, GD + CSB and GD - CSB presented similarly in many ways, suggesting categorical similarities between behavioral and substance use addictions. Thus, these findings support a model, which conceptualizes CSBs as an addiction. However, future studies examining the correlates of GD + CSB with measures of compulsivity and comorbidities with impulse-control disorders are needed to provide further support that CSB should be conceptualized as an addiction rather than an impulse-control disorder.

\section{Implications}

The results of this study have important clinical implications. Overall, we found that individuals who present with the dual diagnosis of GD + CSB evidence greater psychopathology compared to those with a sole diagnosis of GD. Unfortunately, treatments tailored for comorbid conditions are often the exception rather than standard clinical care (Mauro, Furr-Holden, Strain, Crum, \& Mojtabai, 2016; Sacks et al., 2013). Thus, co-occurring diagnoses complicate treatment delivery, which are often designed for single diagnoses. Altering treatment to best suit the needs of those with GD + CSB may enhance outcomes for this unique population. Therefore, screening measures should be in place to ensure those with comorbid conditions like GD + CSB are identified and provided with the appropriate treatment to maximize recovery. In addition, these findings may add to the research base necessary to provide empirical data for the decision-making process of including CSB in future versions of the DSM and recognizing the relevance of addiction psychopathology in the manifestation of CSB.

\section{Limitations}

One limitation of this research is that those who participated in this study were treatment-seeking individuals with GD. Although studying this population provides important clinical information, we are unable to generalize our results to 
non-treatment-seeking samples. Second, this study was a cross-sectional design and thus we are unable to draw temporal conclusions with our results. We also acknowledge that our sample of individuals with GD + CSB was comparatively smaller than our sample of individuals with GD - CSB. Although our ratio of participants with $\mathrm{GD}+\mathrm{CSB}$ to GD - CSB is larger than in previous research (Grant \& Steinberg, 2005), such discrepant sample sizes are not uncommon when studying these unique populations. In addition, one participant who endorsed three or more dimensions on Goodman's criteria was excluded due to clinician judgment. However, we do not have the record that describes the reasons for their exclusion and thus are unable to confirm the clinician's reasoning for excluding this participant. Finally, the DSM-IV criteria were used to diagnose GD. This prior version of the DSM classified GD as a disorder of impulse control. However, GD is presently understood through the lens of an addictive disorder. That said, the DSM-IV criteria (American Psychiatric Association $[\mathrm{APA}], 1994)$ are virtually identical to the DSM-5 criteria (APA, 2013), except for the criteria assessing engagement in illegal acts, which was removed in the DSM-5. Otherwise, despite being classified under different categories, GD is similarly described as an addiction in both diagnostic manuals (e.g., preoccupation, tolerance, and withdrawal), providing some confidence in our findings. Notwithstanding the noted limitations, this study has important strengths including our recruitment from a large clinical population of disordered gamblers and the use of clinical interviews as a more rigorous means of diagnosing psychiatric disorders.

\section{CONCLUSIONS}

Increasingly, addictions are being conceptualized by their commonalities as opposed to their differences (Griffiths, 2005) and in treatment to target the commonalities (Kim \& Hodgins, 2018). This conceptualization of addiction can help clarify the high rates of comorbidity and similarities that often occur among the addictive disorders. Although individuals with GD + CSB and GD - CSB did not differ in certain respects, those with comorbid GD $+\mathrm{CSB}$ evidenced greater psychopathology, a finding that should not be dismissed. Understanding the demographic, clinical, and personality correlates of co-occurring disorders is essential for expanding our understanding of psychopathology, ultimately allowing for the further development of appropriate, tailored treatments for the often-neglected comorbid conditions.

Funding sources: No financial support was received for this study.

Authors' contribution: MEC was involved in conceptualizing the manuscript, data analyses and interpretation, and in the writing of the manuscript. HSK was involved in assisting with data collection, helping to conceptualize the manuscript, assisting with data analysis and interpretation, and editing and reviewing of the manuscript. DCH, DSM, and
MDTS were responsible for editing and reviewing of the manuscript. HT was responsible for assisting with data collection and editing and reviewing of the manuscript. All authors had full access to all data and take responsibility for the integrity of the data and the accuracy of the data analysis.

Conflict of interest: HT has worked for the Federal Bank of Brazil (CAIXA) since March 2015 until February 2018 as a responsible gambling consultant for its national lottery products and as a member of the Independent Assessment Panel for the responsible gambling certification of the World Lottery Association from October 2015 to February 2016. Otherwise, the authors declare they have no other conflicts of interest.

\section{REFERENCES}

Abdollahnejad, R., Delfabbro, P., \& Denson, L. (2014). Psychiatric co-morbidity in problem and pathological gamblers: Investigating the confounding influence of alcohol use disorder. Addictive Behaviors, 39(3), 566-572. doi:10.1016/j.addbeh. 2013.11.004

American Psychiatric Association [APA]. (1994). Diagnostic and statistical manual of mental disorders (4th ed.). Arlington, VA: American Psychiatric Publishing, Inc.

American Psychiatric Association [APA]. (2013). Diagnostic and statistical manual of mental disorders (5th ed.). Arlington, VA: American Psychiatric Publishing, Inc.

Amorim, P. (2000). Mini International Neuropsychiatric Interview (MINI): Validação de entrevista breve para diagnóstico de transtornos mentais [Mini International Neuropsychiatric Interview (MINI): Validation of a short structured diagnostic psychiatric interview]. Revista Brasileira de Psiquiatria, 22(3), 106-115. doi:10.1590/S1516-44462000000300003

Bancroft, J., \& Vukadinovic, Z. (2004). Sexual addiction, sexual compulsivity, sexual impulsivity, or what? Toward a theoretical model. The Journal of Sex Research, 41(3), 225-234. doi:10.1080/00224490409552230

Basiaux, P., Le Bon, O., Dramaix, M., Massat, I., Souery, D., Mendlewicz, J., Pelc, I., \& Verbanck, P. (2001). Temperament and Character Inventory (TCI) personality profile and sub-typing in alcoholic patients: A controlled study. Alcohol \& Alcoholism, 36(6), 584-587. doi:10.1093/alcalc/36.6.584

Berg, K. C., Crosby, R. D., Cao, L., Peterson, C. B., Engel, S. G., Mitchell, J. E., \& Wonderlich, S. A. (2013). Facets of negative affect prior to and following binge-only, purge-only, and binge/ purge events in women with bulimia nervosa. Journal of Abnormal Psychology, 122(1), 111-118. doi:10.1037/a0029703

Billieux, J., Schimmenti, A., Khazaal, Y., Maurage, P., \& Heeren, A. (2015). Are we overpathologizing everyday life? A tenable blueprint for behavioral addiction research. Journal of Behavioral Addictions, 4(3), 119-123. doi:10.1556/2006.4.2015.009

Black, D. W., Coryell, W. H., Crowe, R. R., Shaw, M., McCormick, B., \& Allen, J. (2015). Personality disorders, impulsiveness, and novelty seeking in persons with DSM-IV pathological gambling and their first-degree relatives. Journal of Gambling Studies, 31(4), 1201-1214. doi:10.1007/s10899014-9505-y 
Black, D. W., Kehrberg, L. L. D., Flumerfelt, D. L., \& Schlosser, S. S. (1997). Characteristics of 36 subjects reporting compulsive sexual behavior. American Journal of Psychiatry, 154(2), 243-249. doi:10.1176/ajp.154.2.243

Black, D. W., \& Moyer, T. (1998). Clinical features and psychiatric comorbidity of subjects with pathological gambling behavior. Psychiatric Services, 49(11), 1434-1439. doi:10.1176/ps.49. 11.1434

Blaszczynski, A., \& Nower, L. (2002). A pathways model of problem and pathological gambling. Addiction, 97(5), 487-499. doi:10.1046/j.1360-0443.2002.00015.x

Boothby, C. A., Kim, H. S., Romanow, N. K., Hodgins, D. C., \& McGrath, D. S. (2017). Assessing the role of impulsivity in smoking \& non-smoking disordered gamblers. Addictive Behaviors, 70, 35-41. doi:10.1016/j.addbeh.2017.02.002

Cashwell, C. S., Giordano, A. L., King, K., Lankford, C., \& Henson, R. K. (2017). Emotion regulation and sex addiction among college students. International Journal of Mental Health and Addiction, 15(1), 16-27. doi:10.1007/s11469016-9646-6

Chatzittofis, A., Arver, S., Öberg, K., Hallberg, J., Nordström, P., \& Jokinen, J. (2016). HPA axis dysregulation in men with hypersexual disorder. Psychoneuroendocrinology, 63, 247-253. doi:10.1016/j.psyneuen.2015.10.002

Christo, G., Jones, S. L., Haylett, S., Stephenson, G. M., Lefever, R. M. H., \& Lefever, R. (2003). The Shorter PROMIS Questionnaire: Further validation of a tool for simultaneous assessment of multiple addictive behaviours. Addictive Behaviors, 28(2), 225-248. doi:10.1016/S0306-4603(01) 00231-3

Cloninger, R. C., Przybeck, T. R., Svrakic, D. M., \& Wetzel, R. D. (1994). The Temperament and Character Inventory (TCI): A guide to its development and use. St. Louis, MO: Centre for Psychobiology of Personality.

Conway, K. P., Compton, W., Stinson, F. S., \& Grant, B. F. (2006). Lifetime comorbidity of DSM-IV mood and anxiety disorders and specific drug use disorders: Results from the National Epidemiologic Survey on Alcohol and Related Conditions. Journal of Clinical Psychiatry, 67(2), 247-258. doi:10.4088/ JCP.v67n0211

Cunningham-Williams, R. M., Cottler, L. B., Compton, W. M., Spitznagel, E. L., \& Ben-Abdallah, A. (2000). Problem gambling and comorbid psychiatric and substance use disorders among drug users recruited from drug treatment and community settings. Journal of Gambling Studies, 16(4), 347-376. doi:10.1023/A:1009428122460

Cyders, M. A., \& Smith, G. T. (2008). Emotion-based dispositions to rash action: Positive and negative urgency. Psychological Bulletin, 134(6), 807-828. doi:10.1037/a0013341

de Vries, S.-K., \& Meule, A. (2016). Food addiction and bulimia nervosa: New data based on the Yale Food Addiction Scale 2.0. European Eating Disorders Review, 24(6), 518-522. doi:10.1002/erv.2470

do Amaral, M. L. S., Abdo, C. H. N., Tavares, H., \& Scanavino, M. D. T. (2015). Personality among sexually compulsive men who practice intentional unsafe sex in São Paulo, Brazil. The Journal of Sexual Medicine, 12(2), 557-566. doi:10.1111/ jsm. 12761

Evenden, J. L. (1999). Varieties of impulsivity. Psychopharmacology, 146(4), 348-361. doi:10.1007/PL00005481
Farré, J. M., Fernández-Aranda, F., Granero, R., Aragay, N., Mallorquí-Bague, N., Ferrer, V., More, A., Bouman, W. P., Arcelus, J., Savvidou, L. G., Penelo, E., Aymamí, M. N., Gómez-Peña, M., Gunnard, K., Romaguera, A., Menchón, J. M., Vallès, V., \& Jiménez-Murcia, S. (2015). Sex addiction and gambling disorder: Similarities and differences. Comprehensive Psychiatry, 56, 59-68. doi:10.1016/j.comppsych. 2014.10.002

Farstad, S. M., von Ranson, K. M., Hodgins, D. C., El-Guebaly, N., Casey, D. M., \& Schopflocher, D. P. (2015). The influence of impulsiveness on binge eating and problem gambling: A prospective study of gender differences in Canadian adults. Psychology of Addictive Behaviors, 29(3), 805-812. doi:10.1037/adb0000069

Fischer, S., \& Smith, G. T. (2008). Binge eating, problem drinking, and pathological gambling: Linking behavior to shared traits and social learning. Personality and Individual Differences, 44(4), 789-800. doi:10.1016/j.paid.2007.10.008

Forbush, K. T., Shaw, M., Graeber, M. A., Hovick, L., Meyer, V. J., Moser, D. J., Bayless, J., Watson, D., \& Black, D. W. (2008). Neuropsychological characteristics and personality traits in pathological gambling. CNS Spectrums, 13(4), 306-315. doi:10.1017/S1092852900016424

Fuentes, D., Tavares, H., Camargo, C. H. P., \& Gorenstein, C. (2000). Inventário de Temperamento e Caráter de CloningerValidação da versão em Português [Cloninger's temperament and Character Inventory - Validation of a Portuguese version]. In C. Gorenstein, L. H. S. G. Andrade, \& A. W. Zuardi (Eds.), Escalas de avaliação clínica em psiquiatria e psicofarmacologia [Scales of clinical evaluation in psychiatry and psychopharmacology] (pp. 363-376). São Paulo: Lemos Editorial.

Galetti, A. M., \& Tavares, H. (2017). Development and validation of the Gambling Follow-up Scale, Self-Report version: An outcome measure in the treatment of pathological gambling. Revista Brasileira de Psiquiatria, 39(1), 36-44. doi:10.1590/ 1516-4446-2016-1911

González-Bueso, V., Santamaría, J. J., Fernández, D., Merino, L., Montero, E., \& Ribas, J. (2018). Association between Internet gaming disorder or pathological video-game use and comorbid psychopathology: A comprehensive review. International Journal of Environmental Research and Public Health, 15(4), 668. doi:10.3390/ijerph15040668

Goodman, A. (2001). What's in a name? Terminology for designating a syndrome of driven sexual behavior. Sexual Addiction \& Compulsivity, 8(3-4), 191-213. doi:10.1080/ 107201601753459919

Goodman, A. (2005). Sexual addiction: Nosology, diagnosis, etiology, and treatment. In J. H. Lowinson, P. Ruiz, R. B. Millman, \& J. G. Langrod (Eds.), Substance abuse (pp. 505-539). Philadelphia, PA: Lippincott Williams \& Wilkins.

Granero, R., Fernández-Aranda, F., Mestre-Bach, G., Steward, T., Baño, M., del Pino-Gutiérrez, A., Moragas, L., MallorquíBagué, N., Aymamí, N., Gómez-Peña, M., Tárrega, S., Menchón, J. M., \& Jiménez-Murcia, S. (2016). Compulsive buying behavior: Clinical comparison with other behavioral addictions. Frontiers in Psychology, 7, 914. doi:10.3389/ fpsyg.2016.00914

Grant, J. E. (2008). Impulse control disorders: A clinician's guide to understanding and treatment behavioral addictions (1st ed.). New York, NY: W. W. Norton \& Co. 
Grant, J. E., \& Kim, S. W. (2002). Clinical characteristics and associated psychopathology of 22 patients with kleptomania. Comprehensive Psychiatry, 43(5), 378-384. doi:10.1053/ comp. 2002.34628

Grant, J. E., \& Kim, S. W. (2003). Comorbidity of impulse control disorders in pathological gamblers. Acta Psychiatrica Scandinavica, 108(3), 203-207. doi:10.1034/j.1600-0447.2003. 00162. $\mathrm{x}$

Grant, J. E., \& Steinberg, M. A. (2005). Compulsive sexual behavior and pathological gambling. Sexual Addiction \& Compulsivity, 12(2-3), 235-244. doi:10.1080/107201605 00203856

Griffiths, M. (2005). A 'components' model of addiction within a biopsychosocial framework. Journal of Substance Use, 10(4), 191-197. doi:10.1080/14659890500114359

Hodgins, D. C., \& el-Guebaly, N. (2010). The influence of substance dependence and mood disorders on outcome from pathological gambling: Five-year follow-up. Journal of Gambling Studies, 26(1), 117-127. doi:10.1007/s10899-0099137-9

Hodgins, D. C., \& Holub, A. (2015). Components of impulsivity in gambling disorder. International Journal of Mental Health and Addiction, 13(6), 699-711. doi:10.1007/s11469-015-9572-z

Hodgins, D. C., Stea, J. N., \& Grant, J. E. (2011). Gambling disorders. The Lancet, 378(9806), 1874-1884. doi:10.1016/ S0140-6736(10)62185-X

Hollander, E. (1993). Obsessive-compulsive spectrum disorders: An overview. Psychiatric Annals, 23(7), 355-358. doi:10.3928/ 0048-5713-19930701-05

Hollander, E. (2005). Obsessive-compulsive disorder and spectrum across the life span. International Journal of Psychiatry in Clinical Practice, 9(2), 79-86. doi:10.1080/ 13651500510018347

Hollander, E., \& Wong, C. M. (1995a). Body dysmorphic disorder, pathological gambling, and sexual compulsions. The Journal of Clinical Psychiatry, 56(Suppl. 4), 7-12.

Hollander, E., \& Wong, C. M. (1995b). Obsessive-compulsive spectrum disorders. The Journal of Clinical Psychiatry, 56(Suppl. 4), 3-6.

Hsieh, Y. P., Shen, A. C. T., Wei, H. S., Feng, J. Y., Huang, S. C. Y., \& Hwa, H. L. (2016). Associations between child maltreatment, PTSD, and Internet addiction among Taiwanese students. Computers in Human Behavior, 56, 209-214. doi:10.1016/j.chb.2015.11.048

Janiri, L., Martinotti, G., Dario, T., Schifano, F., \& Bria, P. (2007). The gamblers' Temperament and Character Inventory (TCI) personality profile. Substance Use \& Misuse, 42(6), 975-984. doi:10.1080/10826080701202445

Jauregui, P., Estévez, A., \& Urbiola, I. (2016). Pathological gambling and associated drug and alcohol abuse, emotion regulation, and anxious-depressive symptomatology. Journal of Behavioral Addictions, 5(2), 251-260. doi:10.1556/2006. 5.2016 .038

Jiménez-Murcia, S., Fernández-Aranda, F., Granero, R., Chóliz, M., La Verde, M., Aguglia, E., Signorelli, M. S., Sá, G. M., Aymamí, N., Gómez-Peña, M., del Pino-Gutiérrez, M., Moragas, L., Fagundo, A. B., Sauchelli, S., FernándezFormoso, J. A., \& Menchón, J. M. (2014). Video game addiction in gambling disorder: Clinical, psychopathological, and personality correlates. BioMed Research International, 2014, 315062. doi:10.1155/2014/315062
Jiménez-Murcia, S., Granero, R., Tárrega, S., Angulo, A., Fernández-Aranda, F., Arcelus, J., Fernández-Aranda, F., Arcelus, J., Fagundo, A. B., Aymami, N. M., Moragas, L., Sauvaget, A., Grall-Bronnec, M., Gómez-Peña, M., \& Menchón, J. M. (2016). Mediational role of age of onset in gambling disorder, a path modeling analysis. Journal of Gambling Studies, 32(1), 327-340. doi:10.1007/s10899-0159537-y

Kafka, M. P. (2010). Hypersexual disorder: A proposed diagnosis for DSM-V. Archives of Sexual Behavior, 39(2), 377-400. doi:10.1007/s10508-009-9574-7

Kessler, R. C., Hwang, I., LaBrie, R., Petukhova, M., Sampson, N. A., Winters, K. C., \& Shaffer, H. J. (2008). DSM-IV pathological gambling in the National Comorbidity Survey Replication. Psychological Medicine, 38(9), 1351-1360. doi:10.1017/S0033291708002900

Kessler, R. C., Sonnega, A., Bromet, E., Hughes, M., \& Nelson, C. B. (1995). Posttraumatic stress disorder in the National Comorbidity Survey. Archives of General Psychiatry, 52(12), 1048-1060. doi:10.1001/archpsyc.1995.03950240066012

Kim, H. S., \& Hodgins, D. C. (2018). Component model of addiction treatment: A pragmatic transdiagnostic treatment model of behavioral and substance addictions. Frontiers in Psychiatry, 9, 406. doi:10.3389/fpsyt.2018.00406

Kim, S. W., Grant, J. E., Potenza, M. N., Blanco, C., \& Hollander, E. (2009). The Gambling Symptom Assessment Scale (G-SAS): A reliability and validity study. Psychiatry Research, 166(1), 76-84. doi:10.1016/j.psychres.2007.11.008

Kraus, S. W., Voon, V., \& Potenza, M. N. (2016). Should compulsive sexual behavior be considered an addiction? Addiction, 111(12), 2097-2106. doi:10.1111/add.13297

Kühn, S., \& Gallinat, J. (2014). Brain structure and functional connectivity associated with pornography consumption: The brain on porn. JAMA Psychiatry, 71(7), 827-834. doi:10.1001/ jamapsychiatry.2014.93

Lacey, J. H., \& Evans, C. D. H. (1986). The impulsivist: A multiimpulsive personality disorder. British Journal of Addiction, 81(5), 641-649. doi:10.1111/j.1360-0443.1986.tb00382.x

Ladd, G. T., \& Petry, N. M. (2003). A comparison of pathological gamblers with and without substance abuse treatment histories. Experimental and Clinical Psychopharmacology, 11(3), 202-209. doi:10.1037/1064-1297.11.3.202

Leblond, J., Ladouceur, R., \& Blaszczynski, A. (2003). Which pathological gamblers will complete treatment? British Journal of Clinical Psychology, 42(2), 205-209. doi:10.1348/ 014466503321903607

Lecrubier, Y., Sheehan, D., Weiller, E., Amorim, P., Bonora, I., Harnett Sheehan, K., Janavs, J., \& Dunbar, G. (1997). The Mini International Neuropsychiatric Interview (MINI). A short diagnostic structured interview: Reliability and validity according to the CIDI. European Psychiatry, 12(5), 224-231. doi:10.1016/S0924-9338(97)83296-8

Lorains, F. K., Cowlishaw, S., \& Thomas, S. A. (2011). Prevalence of comorbid disorders in problem and pathological gambling: Systematic review and meta-analysis of population surveys. Addiction, 106(3), 490-498. doi:10.1111/j.13600443.2010.03300.x

Malloy-Diniz, L. F., Mattos, P., Leite, W. B., Abreu, N., Coutinho, G., de Paula, J. J., Tavaresv, H., Vasconcelos, A. G., \& Fuentes, D. (2010). Tradução e adaptação cultural da Barratt Impulsiveness Scale (BIS-11) para aplicação em adultos 
brasileiros [Translation and cultural adaptation of Barratt Impulsiveness Scale (BIS-11) for administration in Brazilian adults]. Jornal Brasileiro de Psiquiatria, 59(2), 99-105. doi:10.1590/S0047-20852010000200004

Martinotti, G., Andreoli, S., Giametta, E., Poli, V., Bria, P., \& Janiri, L. (2006). The dimensional assessment of personality in pathologic and social gamblers: The role of novelty seeking and self-transcendence. Comprehensive Psychiatry, 47(5), 350-356. doi:10.1016/j.comppsych.2005.12.005

Mauro, P. M., Furr-Holden, C. D., Strain, E. C., Crum, R. M., \& Mojtabai, R. (2016). Classifying substance use disorder treatment facilities with co-located mental health services: A latent class analysis approach. Drug and Alcohol Dependence, 163, 108-115. doi:10.1016/j.drugalcdep.2016.04.001

McElroy, S. L., Phillips, K. A., \& Keck, J. P. E. (1994). Obsessive compulsive spectrum disorder. The Journal of Clinical Psychiatry, 55, 33-51.

Mechelmans, D. J., Irvine, M., Banca, P., Porter, L., Mitchell, S., Mole, T. B., Lapa, T. R., Harrison, N. A., Potenza, M. N., \& Voon, V. (2014). Enhanced attentional bias towards sexually explicit cues in individuals with and without compulsive sexual behaviours. PLoS One, 9(8), e105476. doi:10.1371/journal. pone. 0105476

Miner, M. H., Raymond, N., Mueller, B. A., Lloyd, M., \& Lim, K. O. (2009). Preliminary investigation of the impulsive and neuroanatomical characteristics of compulsive sexual behavior. Psychiatry Research, 174(2), 146-151. doi:10.1016/j. pscychresns.2009.04.008

Moon, M., Lister, J. J., Milosevic, A., \& Ledgerwood, D. M. (2017). Subtyping non-treatment-seeking problem gamblers using the pathways model. Journal of Gambling Studies, 33(3), 841-853. doi:10.1007/s10899-016-9658-y

Nordin, C., \& Nylander, P. O. (2007). Temperament and character in pathological gambling. Journal of Gambling Studies, 23(2), 113-120. doi:10.1007/s10899-006-9049-x

Parsons, J. T., Rendina, H. J., Ventuneac, A., Cook, K. F., Grov, C., \& Mustanski, B. (2013). A psychometric investigation of the Hypersexual Disorder Screening Inventory among highly sexually active gay and bisexual men: An item response theory analysis. The Journal of Sexual Medicine, 10(12), 3088-3101. doi: $10.1111 /$ jsm. 12117

Patton, J. H., Stanford, M. S., \& Barratt, E. S. (1995). Factor structure of the Barratt Impulsiveness Scale. Journal of Clinical Psychology, 51(6), 768-774. doi:10.1002/1097-4679 (199511)51:6<768::AID-JCLP2270510607>3.0.CO;2-1

Peluso, M. A. M., Hatch, J. P., Glahn, D. C., Monkul, E. S., Sanches, M., Najt, P., Bowden, C. L., Barratt, E. S., \& Soares, J. C. (2007). Trait impulsivity in patients with mood disorders. Journal of Affective Disorders, 100(1-3), 227-231. doi:10.1016/j.jad.2006.09.037

Petry, N. M. (2003). Validity of a Gambling Scale for the Addiction Severity Index. The Journal of Nervous and Mental Disease, 191(6), 399-407. doi:10.1097/01.NMD.000007 1589.20829.DB

Politis, M., Loane, C., Wu, K., O'sullivan, S. S., Woodhead, Z., Kiferle, L., Lawrence, A. D., Lees, A. J., \& Piccini, P. (2013). Neural response to visual sexual cues in dopamine treatmentlinked hypersexuality in Parkinson's disease. Brain, 136(2), 400-411. doi:10.1093/brain/aws326

Raymond, N. C., Coleman, E., \& Miner, M. H. (2003). Psychiatric comorbidity and compulsive/impulsive traits in compulsive sexual behavior. Comprehensive Psychiatry, 44(5), 370-380. doi:10.1016/S0010-440X(03)00110-X

Reid, R. C., Carpenter, B. N., Hook, J. N., Garos, S., Manning, J. C., Gilliland, R., Cooper, E. B., McKittrick, H., Davtian, M., \& Fong, T. (2012). Report of findings in a DSM-5 field trial for hypersexual disorder. The Journal of Sexual Medicine, 9(11), 2868-2877. doi:10.1111/j.1743-6109.2012.02936.x

Sacks, S., Chaple, M., Sirikantraporn, J., Sacks, J. Y., Knickman, J., \& Martinez, J. (2013). Improving the capability to provide integrated mental health and substance abuse services in a state system of outpatient care. Journal of Substance Abuse Treatment, 44(5), 488-493. doi:10.1016/j.jsat.2012.11.001

Scanavino, M. D. T., Ventuneac, A., Rendina, H. J., Abdo, C. H. N., Tavares, H., do Amaral, M. L. S., Messina, B., Reis, S. C., Martins, J. P., Gordon, M. C., Vieira, J. C., \& Parsons, J. T. (2016). Sexual Compulsivity Scale, Compulsive Sexual Behavior Inventory, and Hypersexual Disorder Screening Inventory: Translation, adaptation, and validation for use in Brazil. Archives of Sexual Behavior, 45(1), 207-217. doi:10.1007/s10508-014-0356-5

Shaffer, H. J., LaPlante, D. A., LaBrie, R. A., Kidman, R. C., Donato, A. N., \& Stanton, M. V. (2004). Toward a syndrome model of addiction: Multiple expressions, common etiology. Harvard Review of Psychiatry, 12(6), 367-374. doi:10.1080/ 10673220490905705

Smith, G. T., \& Cyders, M. A. (2016). Integrating affect and impulsivity: The role of positive and negative urgency in substance use risk. Drug and Alcohol Dependence, 163, S3-S12. doi:10.1016/j.drugalcdep.2015.08.038

Steel, Z., \& Blaszczynski, A. (1998). Impulsivity, personality disorders and pathological gambling severity. Addiction, 93(6), 895-905. doi:10.1046/j.1360-0443.1998.93689511.x

Steenbergh, T. A., Meyers, A. W., May, R. K., \& Whelan, J. P. (2002). Development and validation of the Gamblers' Beliefs Questionnaire. Psychology of Addictive Behaviors, 16(2), 143-149. doi:10.1037/0893-164X.16.2.143

Tabachnick, B. G., \& Fidell, L. S. (2007). Using multivariate statistics (5th ed.). Boston, MA: Allyn \& Bacon/Pearson Education.

Tagay, S., Schlottbohm, E., Reyes-Rodriguez, M. L., Repic, N., \& Senf, W. (2014). Eating disorders, trauma, PTSD, and psychosocial resources. Eating Disorders, 22(1), 33-49. doi:10.1080/ 10640266.2014.857517

Tavares, H., Martins, S. S., Lobo, D. S. S., Silveira, C. M., Gentil, V., \& Hodgins, D. C. (2003). Factors at play in faster progression for female pathological gamblers: An exploratory analysis. The Journal of Clinical Psychiatry, 64(4), 433-438. doi:10.4088/JCP.v64n0413

Umberg, E. N., Shader, R. I., Hsu, L. K. G., \& Greenblatt, D. J. (2012). From disordered eating to addiction: The food drug in bulimia nervosa. Journal of Clinical Psychopharmacology, 32(3), 376-389. doi:10.1097/JCP.0b013e318252464f

Voon, V., Mole, T. B., Banca, P., Porter, L., Morris, L., Mitchell, S., Lapa, T. R., Karr, J., Harrison, N. A., Potenza, M. N., \& Irvine, M. (2014). Neural correlates of sexual cue reactivity in individuals with and without compulsive sexual behaviours. PLoS One, 9(7), e102419. doi:10.1371/journal.pone.0102419

Williams, A. D., Grisham, J. R., Erskine, A., \& Cassedy, E. (2012). Deficits in emotion regulation associated with pathological gambling. British Journal of Clinical Psychology, 51(2), 223-238. doi:10.1111/j.2044-8260.2011.02022.x 